\title{
Residual Stress Distribution Caused by Laser Hardening and Conventional Quenching in Plain Carbon Steel
}

\author{
A. Filep ${ }^{1, a^{*}}$, M. Benke $e^{2, b}$, V. Mertinger ${ }^{1, c}$, G. Buza ${ }^{3, d}$ \\ ${ }^{1}$ Institute of Physical Metallurgy, Metalforming and Nanotechnology, University of Miskolc, 3515 \\ Miskolc-Egyetemváros, Hungary \\ ${ }^{2}$ MTA-ME Materials Science Research Group, University of Miskolc, Miskolc-Egyetemváros, \\ Hungary \\ ${ }^{3}$ Bay Zoltán Applied Research Nonprofit Ltd., Department of Laser Technology, 1116 Budapest, \\ Fehérvári út 130., Hungary

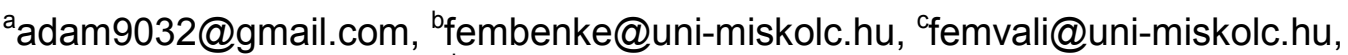 \\ 'gabor.buza@bayzoltan.hu
}

Keywords: laser hardening, residual stress measurement, X-ray diffraction

Abstract Heat transfer during laser hardening occurs from the surface towards the bulk in contrast to conventional quenching, where it occurs from the bulk towards the surrounding. The residual stress distributions due to laser hardening and conventional quenching of plain carbon steel samples were measured using X-ray diffraction. The effect of changing the treatment parameters, that is laser power and feed rate, was examined on the resulting stress distribution. The relationship between the measured stress distribution and the evolved microstructure is established.

\section{Introduction}

There are two main sources of residual stresses during the heat treatments of steels. Stresses caused by the transformation of the austenite and thermal stresses caused by the different cooling rates and strain incompatibilities [1,2]. The different heat treating methods apply different timetemperature profiles and energy densities. Thus, the residual stresses and stress profiles resulting from heat treatments can be very complex depending on the type and parameters of the applied heat treatment [3]. During conventional quenching treatments the heat is transferred from the bulk of the part towards the cooling media. Whereas for laser surface hardening, the heat is transferred from the surface towards the bulk [4,5]. Because of the opposing heat transfer of the two types of quenching methods, the examination and comparison of the residual stress profiles formed by the two methods is of great interest. The result of numerical simulation on residual stresses due to the surface hardening available in the literature, but experimental data are lacking [6]. The aim of the present manuscript is to examine the surface and depth stress profiles developed by laser surface hardening treatments, applying different laser power and feed rate. The developed microstructures are also examined. The depth profile is compared to the results obtained by conventional quenching method.

\section{Experimental}

Laser surface hardening treatments were performed with a $5 \mathrm{~kW}$ nominal maximal power $\mathrm{CO}_{2}$ laser equipment on one side of four discs with diameter of $120 \mathrm{~mm}$ and thickness of $22 \mathrm{~mm}$ of hot rolled plain carbon steel. The surface of the discs was spray coated with graphite absorber before the treatments. Different laser power and feed rate were applied during the treatments. Two $20 \mathrm{~mm}$ wide parallel hardened bands, one with $400 \mathrm{~mm} / \mathrm{min}$, the other with $300 \mathrm{~mm} / \mathrm{min}$ feed rate were produced $20 \mathrm{~mm}$ distance from each other on every disc (Fig. 1). The applied laser power was different for each disc varying from $70 \%$ to $100 \%$ (equivalent with $5 \mathrm{~kW}$ ) power. During the conventional quenching $970^{\circ} \mathrm{C}$ for $20 \mathrm{~min}, \mathrm{~N}_{2}$ atmosphere and water cooling agent were used. The residual stress measurements were performed without sample cutting on the surface of the discs using a Stresstech Xstress 3000 G3R X-ray diffractometer with $\mathrm{Cr}$ tube. $1 \mathrm{~mm}$ collimator spot size and 5 inclination angles ranging from $-45^{\circ}$ to $45^{\circ}$ were used to measure the peak shift of the ferrite/martensite $\{211\}$ reflection. The stresses were calculated using $\mathrm{E}_{\{211\}}$ Young's modulus of 
$211000 \mathrm{MPa}$ and Poisson ratio of 0.3 . The initial stress states prior to the treatments were measured in seven points along the centreline of the discs. Since these varied only within the scatter of the measurements for each sample, the initial stress states of the discs were characterized by the averages of seven measurements.

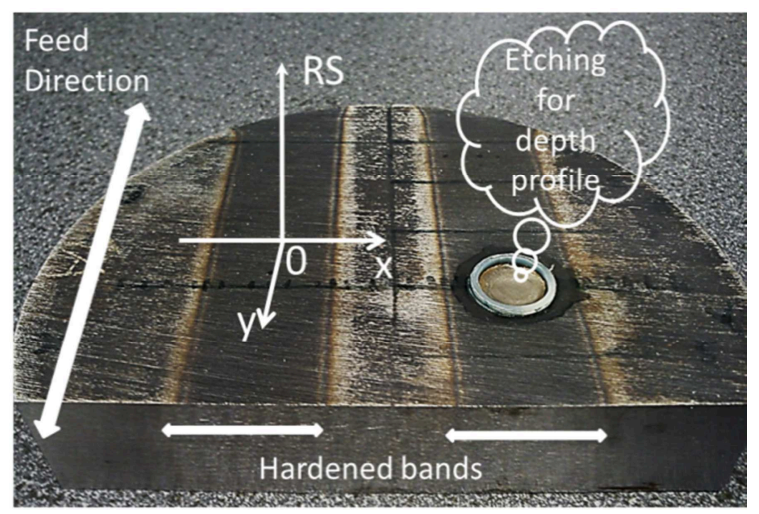

Fig. 1. Part of the laser treated disc, $\mathrm{x}, \mathrm{y}$ distance coordinates, RS-residual stress

The residual stress state of one band formed by the laser treatment was determined about 30 points along the $\mathrm{x}$ axis. The stress was measured in the $\mathrm{x}$ and in the $\mathrm{y}$ direction as well at each measured point. The y direction is parallel while the $\mathrm{x}$ direction is perpendicular with feed direction of laser beam. Not only the normal but the shear stresses were calculated at each point. Depth residual stress profiles were also measured after the laser and after the conventional quenching. For such examinations, a Struers mobile electrolytic polishing equipment was used to remove the surface layers of the material. A Mitutoyo displacement gauge was used for the depth measurements with one $\mu \mathrm{m}$ accuracy. The measured residual stress values due to layer removal were automatically corrected. The microstructure examinations were performed with a Zeiss Axio Imager M1m optical microscope using bright field imaging system.

\section{Results and discussion}

It is predictable that varying the parameters of the laser treatments, the dimension of the treated zones have changed [7-10]. The dimension of the hardened bands can be seen in the Fig. 2. White markers show the half width and the depth of the heat effected zone as a function of laser power $(70-100 \%)$ and feed rate $(400,300 \mathrm{~mm} / \mathrm{min})$.

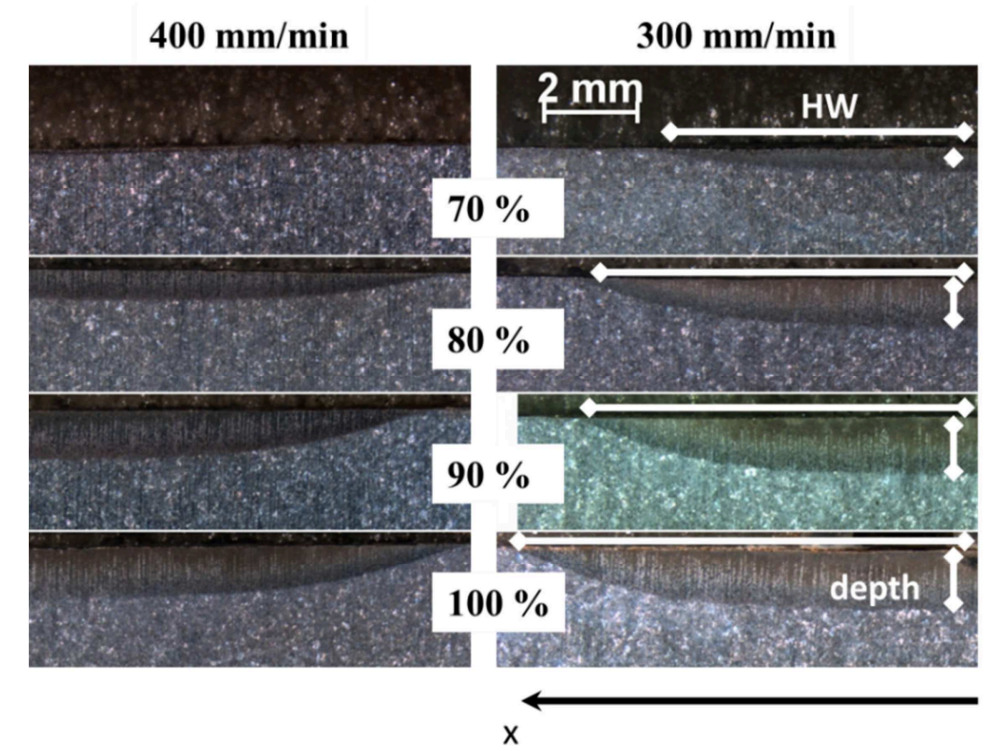

Fig. 2. Half width (HW) and depth dimension of the laser treaded part as a function of laser power $(70-100 \%)$ and feed rate $(400,300 \mathrm{~mm} / \mathrm{min})$ 
Fig. 3 gives an example about the hardened microstructure and shows the measured depth size of the heat effected zone. The initial microstructure consisted of rows of ferrite (white) and pearlite (dark). Due to the banded structure some percent of ferrite was remained in the heat treated volume during the treatment. It can be seen that as the laser power increases, the width and the depth of the hardened region increase. It is also apparent that decreasing the feed rate the width and depth of the hardened region increase.
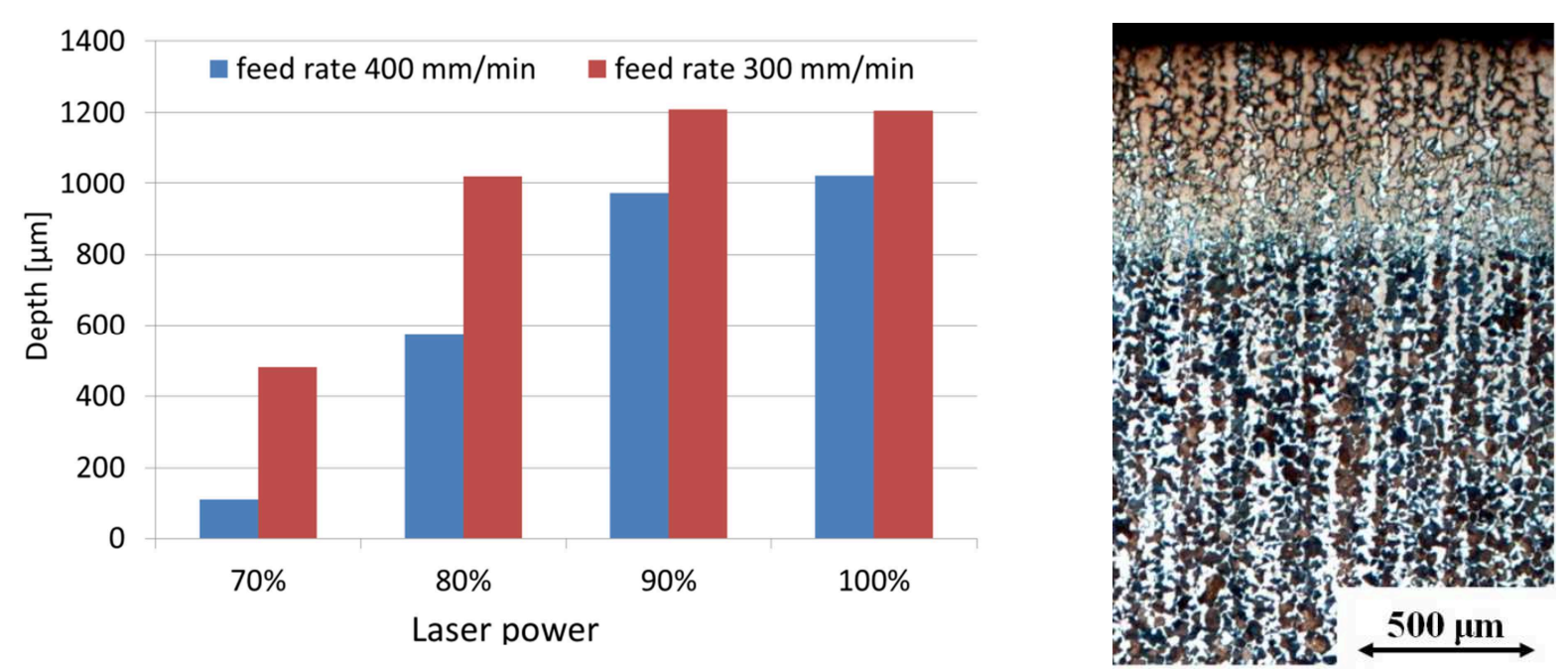

Fig. 3. Depth size of the laser treated part as a function of laser power (70-100\%) and feed rate $(400,300 \mathrm{~mm} / \mathrm{min})$ with a typical microstructure $(400 \mathrm{~mm} / \mathrm{min}$ feed rate, $80 \%$ power $)$

Fig. 4-Fig. 7 series show the measured stress data in case of applied $400 \mathrm{~mm} / \mathrm{min}$ feed rate. The normal and the shear stress are presented in $\mathrm{x}$ and also in y direction at each measuring point. The scatter of the measurements is indicated, the value of those are acceptable in this method. The average of initial stress values prior to the treatments are marked by dashed lines in every cases. There is a weak compressive stress (around -180 MPa) and shear stress (around $60 \mathrm{MPa}$ ) in case of $\mathrm{x}$ direction (Fig. 4, Fig. 5).

After the hardening treatments, a central region was formed, in which the normal stress plateaus have the same values as prior to the treatments (around -100--200 MPa), while the shear stresses are eliminated in this part of the sample. Obviously, this is the hardened region. At the margins of this region, tensile stresses formed being around $600-700 \mathrm{MPa}$ (Fig. 4), whereas the shear stresses reach their initial value (Fig. 5). Leaving the hardened region the normal stresses converge to the initial values. The shape of the stress profiles does not change with varying laser power and feed rate. The width of the central region increases as the power of the treatment increases. There is no significant effect of the applied feed rates on the width of the central region.

Fig. 6 and Fig. 7 show the measured normal and shear stress values formed by the different laser power hardening treatments in y direction. The compressive stresses prior to treatments are somewhat larger in this direction (around -300 MPa) (Fig. 6), while the initial shear stresses are negligible (Fig. 7). The shape of the normal stress profiles measured in $\mathrm{x}$ and $\mathrm{y}$ direction are very similar. The normal stress plateau of the hardened region can again be observed with around -100 $\mathrm{MPa}$ values. However, the maximal values of tensile stresses in y direction are somewhat smaller, being around $500 \mathrm{Mpa}$. The shear stress profiles do not show the same tendency as in $\mathrm{x}$ direction since there were no shear stresses in the discs prior to treatments in y direction. 

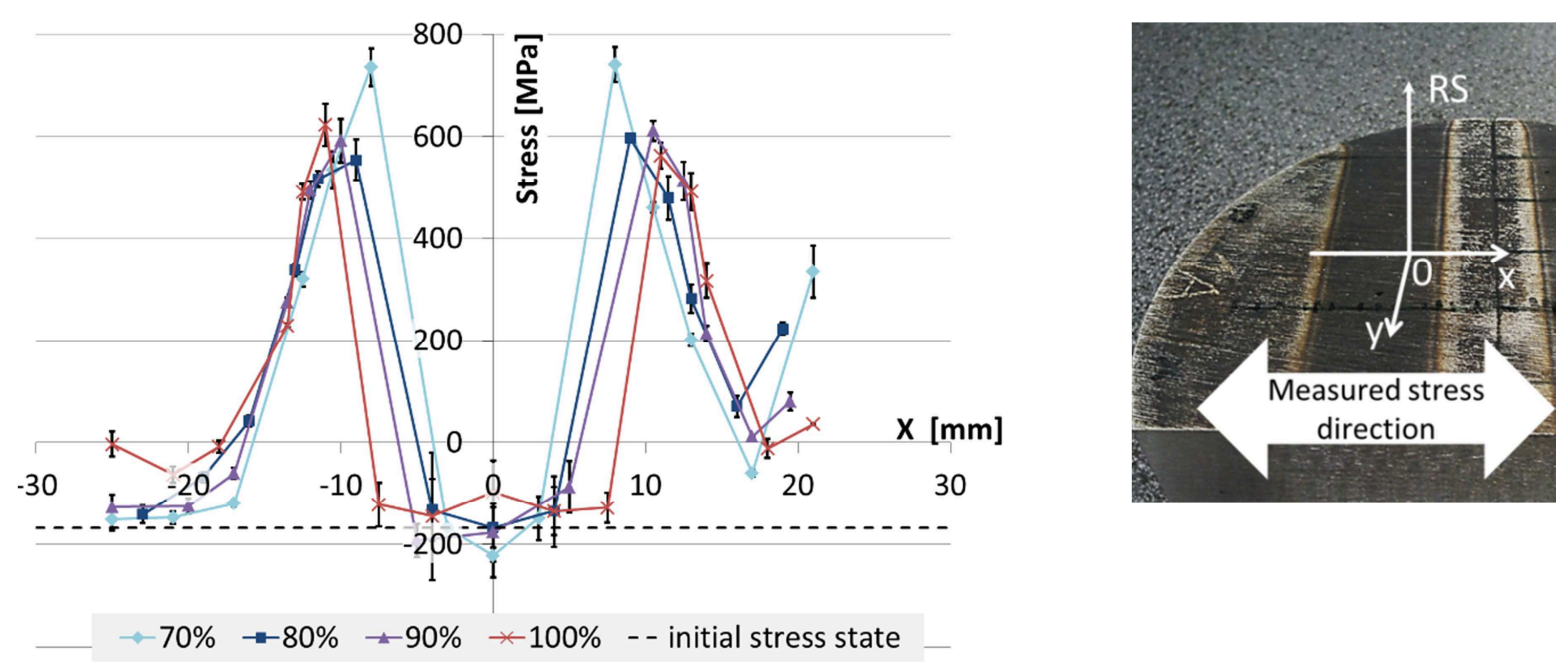

Fig. 4. Residual normal stress profiles in $\mathrm{x}$ direction, along the $\mathrm{x}$ axis, $400 \mathrm{~mm} / \mathrm{min}$ feed rate, 70 $100 \%$ laser power
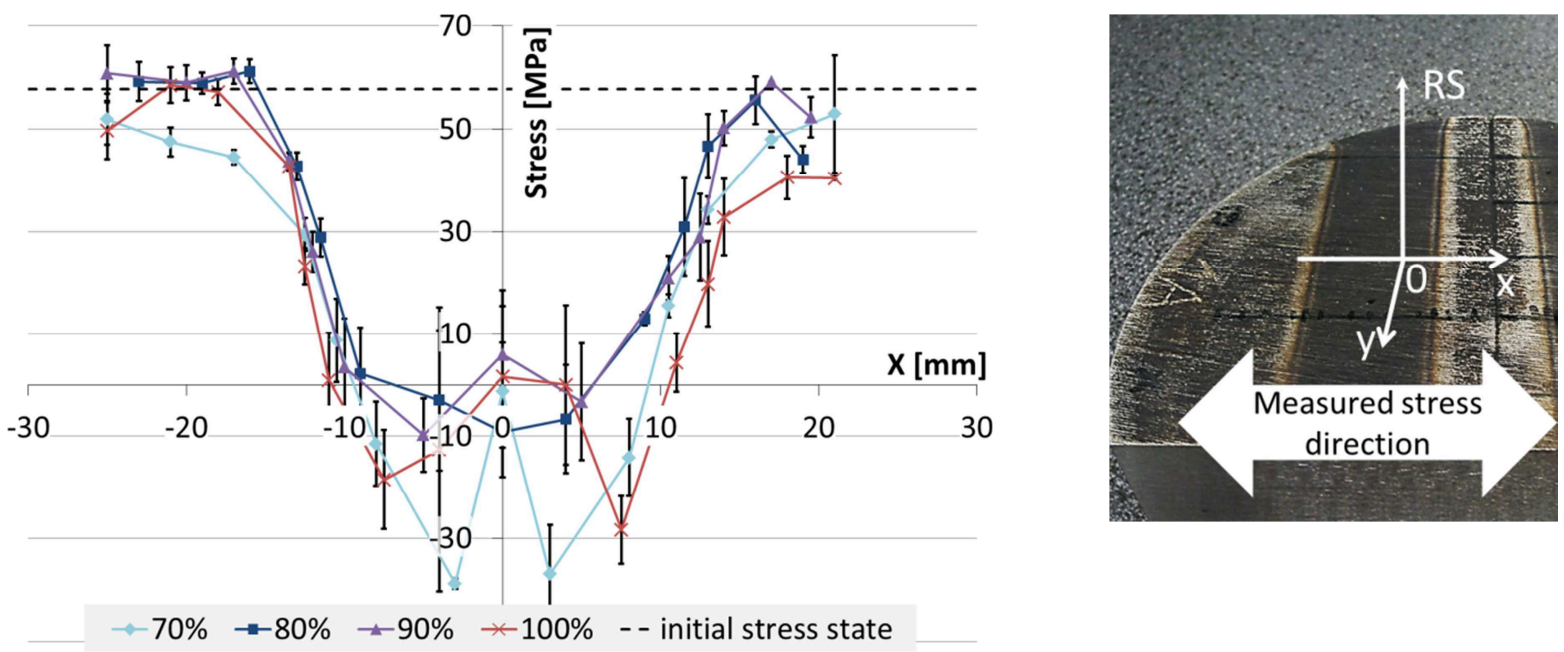

Fig. 5. Residual shear stress profiles in $\mathrm{x}$ direction, along the $\mathrm{x}$ axis, $400 \mathrm{~mm} / \mathrm{min}$ feed rate, $70-100 \%$ laser power
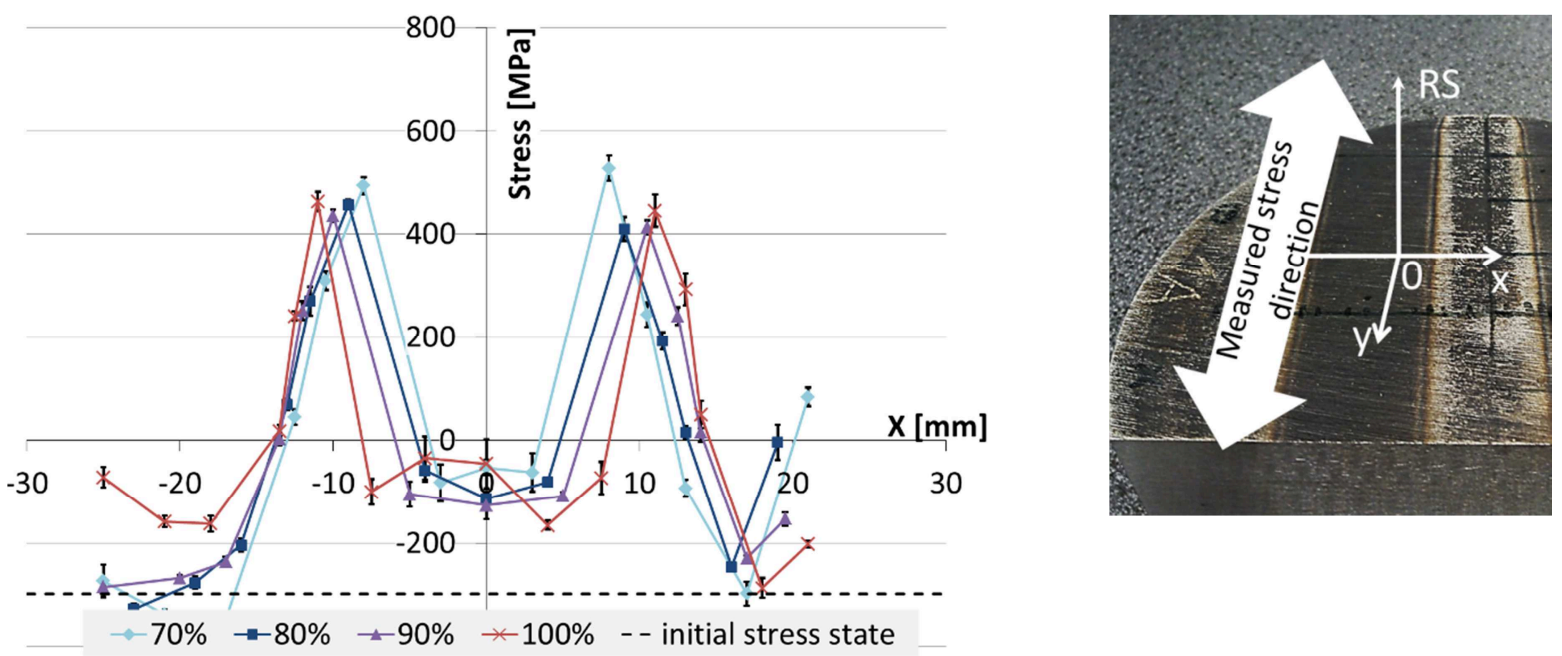

Fig. 6. Residual normal stress profiles in y direction, along the $\mathrm{x}$ axis, $400 \mathrm{~mm} / \mathrm{min}$ feed rate, $70-100 \%$ laser power 

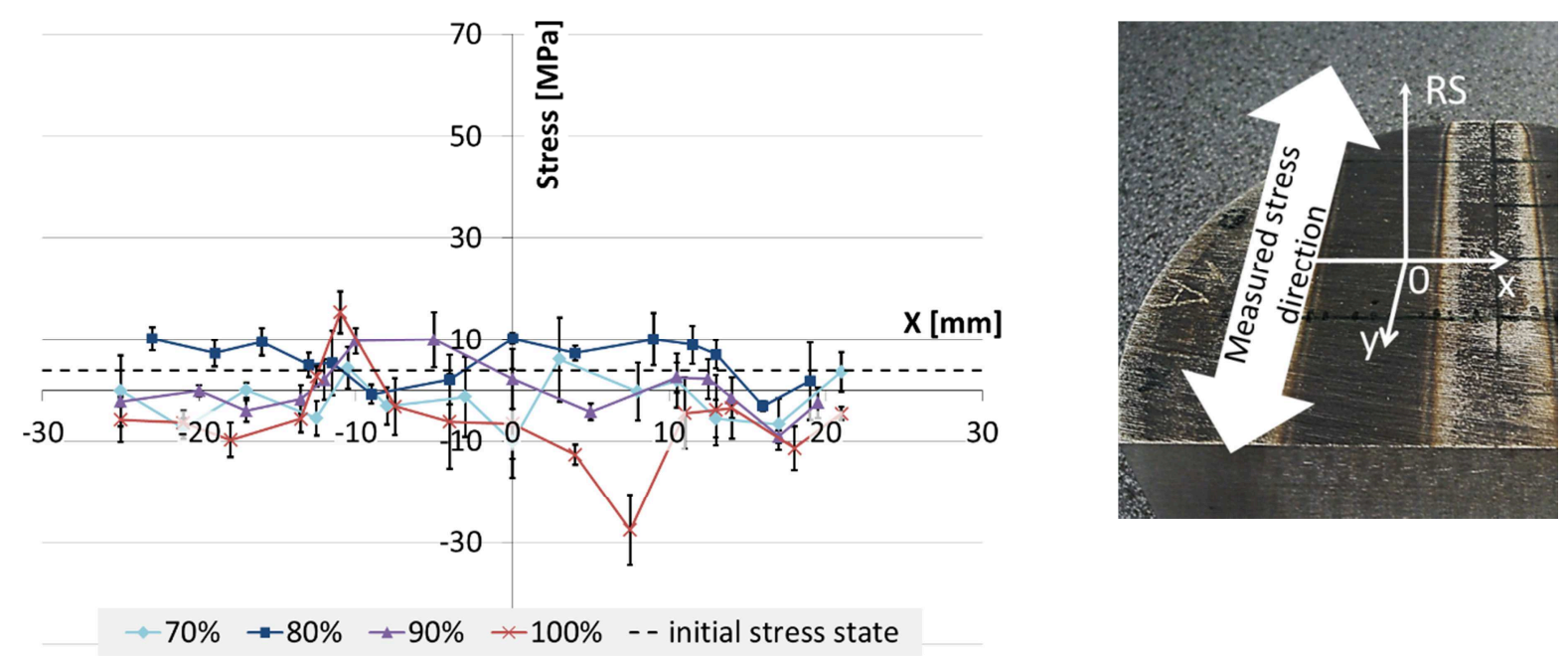

Fig. 7. Residual shear stress profiles in y direction, along the $\mathrm{x}$ axis, $400 \mathrm{~mm} / \mathrm{min}$ feed rate, $70-100 \%$ laser power

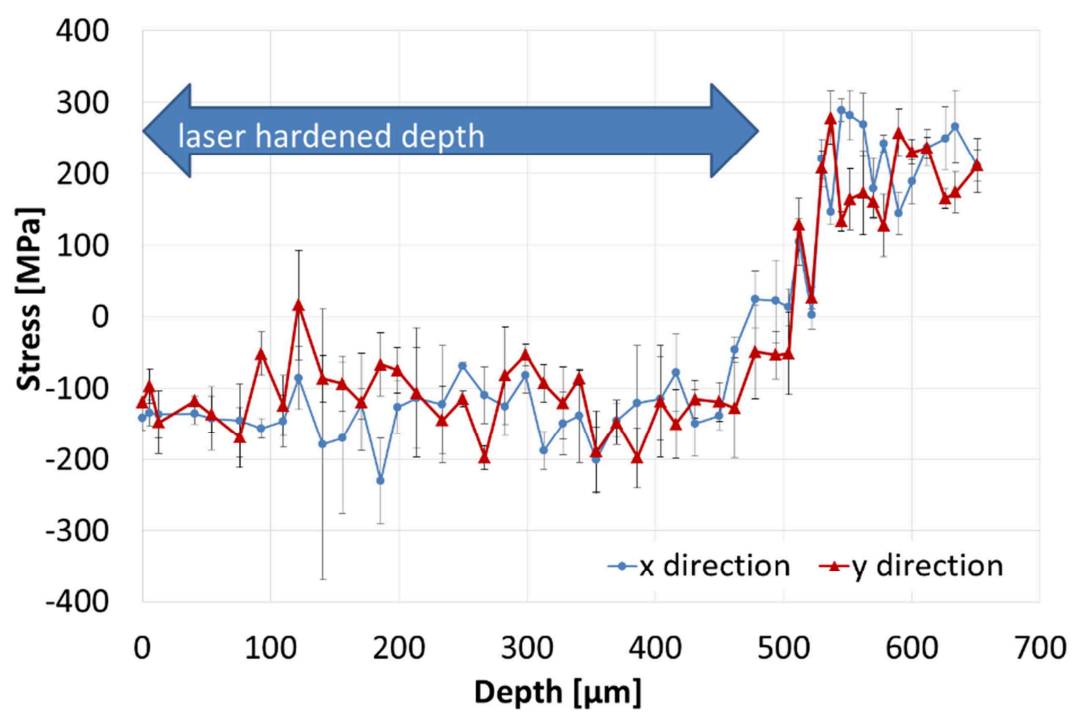

Fig. 8. Residual normal stress depth profiles in $\mathrm{x}$ and $\mathrm{y}$ direction, $300 \mathrm{~mm} / \mathrm{min}$ feed rate, $70 \%$ laser power

Fig. 8 and Fig. 9 represent the depth profiles in both directions, in case of laser hardened and after conventional quenching. The laser hardened sample holds the central region data about $-100 \mathrm{MPa}$ compressive stress up to the margin of heat effected zone $(500 \mu \mathrm{m}$ depth). Under the zone a maximum $300 \mathrm{MPa}$ tensile stress was measured at $650 \mu \mathrm{m}$ depth. The main difference between the results of laser and conventional treating is that a tensile stress with maximum $250 \mathrm{MPa}$ was build up at the surface after conventional quenching which value is decreased in depth. Around $600 \mu \mathrm{m}$, it reaches the stress free state. The normal stress value is a function of direction in that case, (see Fig. $9 \mathrm{x}$ and $\mathrm{y}$ direction) while it is independent after laser treatment (Fig. $8 \mathrm{x}$ and $\mathrm{y}$ direction).

\section{Summary}

Prior to the laser surface hardening treatments the microstructure of the hot rolled plain carbon steel discs consisted of rows of ferrite and pearlite. The stress states of the discs prior to the treatments were produced by the saw cuttings which introduced shear stresses, being somewhat larger in the sawing direction and compressive stresses being larger perpendicular to that direction. 


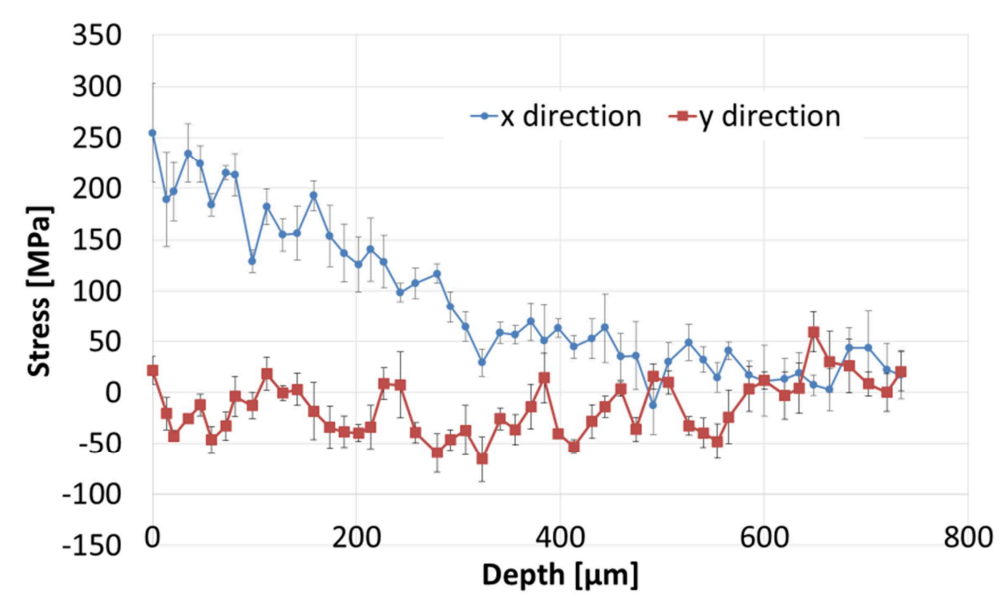

Fig. 9. Residual normal stress depth profiles in $\mathrm{x}$ and $\mathrm{y}$ direction, conventional quenching

During the laser treatments, bands of hardened regions were produced. The surface hardening treatments resulted compressive stresses of $-100--200 \mathrm{MPa}$ within the hardened bands, in which the initially present shear stresses were eliminated. Tensile stresses built up at the margins of the hardened bands at the surface and also under the heat affected zone. It is apparent that the largest stresses formed where the austenized region encountered the non-transformed matrix. The measured stresses are the complex mixtures of the stresses resulting from the transformation of the austenite and the thermal stresses. Both normal and shear stress values converged to the initial values leaving the margins of the bands. Increasing the power of the laser treatments, the hardened band widened and thickened. The same was observed by decreasing the feed rate. The stress state was the opposite in case of conventional quenching. An anisotropic normal tensile stress was built up at the surface, and a stress free state was measured around $600 \mu \mathrm{m}$ in depth.

\section{Acknowledgements}

This work has been carried out as part of the TÁMOP-4.2.1.B-10/2/KONV-2010-0001 project within the framework of the New Hungarian Development Plan. The realization of this project is supported by the European Union, co-financed by the European Social Fund.

\section{References}

[1] Krauss: Principles of Heat Treatment of Steel, ASM Metals Park, Ohio 1980, pp 268

[2] G. Totten, M. Howes, T. Inoue: Handbook of Residual Stress and Deformation of Steel, ASM International, Ohio, 2002

[3] J. R. Davis, ASM Handbook of heat Treatment, ASM International, 1991, USA

[4] Valery Rudnev: Handbook of Induction Heating, Libary of Congress Cataloging - inPublication Data, USA 2003 pp 303

[5] R. E. Haimbaugh, Practical Induction Heat Treating, ASM International, 2001

[6] S. Denis, M. Boufoussi, J. Ch. Chevrier, A. Simon, Analysis of the development of residual stresses for surface hardening of steels by numerical simulation: Effect of process parameters. International Conference on Residual Stresses (ICRS4), Baltimore, MD, Society of Experimental Mechanics, 1994, pp 513-519

[7] J. R. Davis, Surface Hardening of Steels Understanding the Basics, ASM International, 2002

[8] C. Soriano, J. Leunda, J. Lammbarri, V. García Navas, C. Sanz, Effect of Laser Surface Hardening on the Microstructure, hardness and Residual Stresses of Austempered Ductile Iron grades, Applied Surface Science, 257 (2011) 7101-7106

[9] Y. S. Yang, S. J. Na, A Study on Residual Stresses in Laser Surface Hardening of a Medium Carbon Steel, Surface and Coating Technology, 38 (1989) 311-324

[10] G. S. Schajer, Practical Residual Stress Measurement Methods, John Wiley and Sons Ltd., 2013 